\title{
Pattern of Presentation of Neurocutaneous Syndromes in a Tertiary Care Hospital of Bangladesh
}

\author{
GOPEN KUMAR KUNDU ${ }^{1}$, SANJIDA AHMED ${ }^{2}$, SHAHEEN AKHTER ${ }^{3}$, MD NASIR HOSSAIN ${ }^{4}$, RANA \\ KUMAR BISWAS 5
}

\begin{abstract}
Abstact:
Background: Neurocutaneous syndromes (NCS) represent a group of central nervous system disorders associated with lesion in the skin, eye and possibly other visceral organs. Various cutaneous manifestations usually appear early in life, progress with time but neurological features generally present at a later age. The objective of this study is to observe the frequency of pattern and presentation of various forms of neurocutaneous syndrome.
\end{abstract}

Methodology: A descriptive cross sectional study was conducted at department of Paediatric Neurology of Bangabandhu Sheikh Mujib Medical University(BSMMU), Dhaka, Bangladesh from March, 2015 to February, 2016. Children (3month to 8 years) with NCS, diagnosed on the basis of standard diagnostic criteria for different NCS were included and compared.

Results: Among of 27 children,16 (59.26\%) boys, 09(40.74\%) girls with neurocutaneous syndrome, mean age of presentation was $38.67 \pm 18.57$ (range 3 month to 84 months). The various forms of NCS observed were Tuberous sclerosis complex (48.14\%), Ataxia telangiectasia (29.62\%), Sturge Weber Syndrome (14.81\%), Neurofibromatosis1(3.7\%) and Linear nevus syndrome (3.7\%). In Tuberous sclerosis complex , most common feature was facial angiofibroma (92.30\%), Hypomelanotic macule (76.90\%), Shagreen patch (76.90\%). In Ataxia telangiectasia, commonest presentation was ataxia $8(100 \%)$ followed by ocular telangiectasia (62.50\%). In Sturge weber syndrome, commonest presentation was facial capillary malformation (100\%). Neurofibromatosis patient presented with café-au-lait spot (100\%). Common systemic manifestations of NCS were found in TSC and those were multicystic kidney disease (30.76\%), autism spectrum disorder (15.38\%) \& attention deficit hyperactivity disorder (7.69\%).

Conclusion: In our study, the commonest neuro-cutaneous syndrome is tuberous sclerosis complex and it's cutaneous manifestation is facial angiofibroma.

Keywords: Neurocutaneou Syndrome (NCS), Tuberous sclerosis complex (TSC), Neurofibromatosis (NF)

1. Associate Professor, Pediatric Neurology (IPNA), Bangabandhu Sheikh Mujib Medical University, Dhaka.

2. MD Resident Phase-B (Pediatric Neurology), Bangabandhu Sheikh Mujib Medical University, Dhaka

3. Professor, Pediatric Neurology (IPNA), Bangabandhu Sheikh Mujib Medical University, Dhaka

4. Assistant Professor, Department of Pediatrics, Dhaka Medical College \& Hospital, Dhaka

5. MD Resident Phase-B (Pediatric Gastroenterology \& Nutrition), Bangabandhu Sheikh Mujib Medical University, Dhaka

Correspondence: Dr Gopen Kumar Kundu, Associate Professor, Paediatric Neurology, Bangabandhu Sheikh Mujib Medical University, Cell: +8801718590768 Email-gopen.kundu@ gmail.com

Received: 21-07-2018

Accepted: 16-03-2019

\section{Introduction}

Neurocutaneous syndromes (NCS) are heterogeneous group of disorders characterized by abnormalities of both the integument and central nervous system. Most of the disorders of NSC are inherited as autosomal dominant conditions and originated from a defect in differentiation of the primitive ectoderm. ${ }^{1}$ Neurocutaneous disorders are Neurofibromatosis 1 (NF1), tuberous sclerosis complex (TSC), Sturge-weber syndrome (SWS), ataxia-telangiectasia (AT), von hippel-lindau (VHL) disease, PHACE syndrome, linear nevus syndrome (LNS), hypomelanosis of Ito, and Incontinentia 
pigmenti (IP). ${ }^{1}$ Among them most common disorders are neurofibromatosis (NF), tuberous sclerosis complex (TSC), and Sturge-Weber syndrome. These lifelong disorders generally present during infancy and early childhood. So the clinician should be aware of the presenting signs, criteria for diagnosis, role of genetic testing, and approaches to surveillance and management of neurocutaneous syndromes.

Tuberous sclerosis complex (TSC) is an autosomal dominant genetic disorder that is diagnosed from birth to adulthood.TSC is characterized by growth of nonmalignant hamartoma in various organs throughout the body. ${ }^{2}$ The majority of individuals with TSC have mutations in either the TSC1 or TSC2 genes. ${ }^{3,4}$ Most common manifestations of TSC are multiple type of seizures and various organ involvement.

Neurofibromatosis 1 (NF1) is an umbrella term for 3 genetically distinct disorders: NF1, NF2, and Schwannomatosis. They have a common tendency toward development of tumors of the nerve sheath, but the specific manifestations are distinct and the conditions result from variants in different genes. NF1 is the commonest neurofibromatosis and the most likely to present in childhood. Café-au-lait macules are the pathognomonic cutaneous manifestations of NF1 that present at birth but often gradually appear in the first few postnatal months. ${ }^{1,2}$

Ataxia-telangiectasia is a multisystem disorder characterized by progressive deterioration of neurologic function, ocular and cutaneous telangiectasia, cerebellar ataxia and variable immunodeficiency. ${ }^{5}$ Children with AT have an increased chance of sino-pulmonary infection and predisposition to malignancy.

Sturge-weber syndrome is defined as the occurrence of port wine stain on the face associated with leptomeningeal angiomatosis that can lead to seizures, stroke and glaucoma. The port-wine stain can occur without leptomeningeal involvement and leptomeningeal involvement can occur without the port-wine stain. ${ }^{2}$ Though the treatment of NCS is limited but early confirmation of the diagnosis can help ameliorate the likelihood of severe complications.
A quite number of patients of NCS came to our tertiary care hospital. So we decided to conduct this study to evaluate the frequency of pattern and presentation of various forms of neurocutaneous syndrome.

\section{Materials and Methods}

A descriptive cross sectional study was conducted at department of Paediatric Neurology of Bangabandhu Sheikh Mujib Medical University, Dhaka, Bangladesh from March, 2015 to February, 2016. Children with NCS, diagnosed on the basis of standard diagnostic criteria for different NCS were included. Tuberous sclerosis complex (TSC) was confirmed when at least two major or one major plus two minor features were present. Major features included skin lesion, brain and eye lesions and tumors in the heart, lungs and kidneys.Minor features comprised of bone cysts, rectal polyps, dental enamel pits, CNS white matter migrational abnormalities, gingival fibromas, nonrenal hamartomas, retinal acromatic patches, confetti skin lesions and multiple renal cysts. ${ }^{3}$

The diagnosis of neurofibromatosis1 (NF1) was established when two or more of the following features were present: six or more café-au-lait macules over $5 \mathrm{~mm}$ in diameter or more in prepubertal individuals and $15 \mathrm{~mm}$ in diameter or more in postpubertal individuals; two or more neurofibromas or 1 plexiform neurofibroma; inguinal or axillary freckling; optic glioma; two or more Lisch nodules; a distinctive osseous lesion; and a first degree relative with NF1. ${ }^{4}$

Sturge weber syndrome, PHACE syndrome, Ataxia telangiectasia ,hypomelanosis of Ito and Incontinentia pigmenti were diagnosed on the basis of standard clinical features and relevant investigations including neuroimaging, genetic analysis, and skin biopsy, wherever applicable.

All the patients who were evaluated in BSMMU either in-patient or out-patient department were included and data were collected in standard data collected sheet. Statistical analysis was done by SPSS ver. 12.

\section{Results}

Among of 27 children 16(59.26\%) were boys, $09(40.74 \%)$ were girls with neurocutaneous 
syndrome, mean age of presentation was $38.67 \pm 18.57$ (range 3 month to 84 months). The various form of NCS observed were Tuberous sclerosis complex (TSC) $(48.14 \%)$, Ataxia telangiectasia $(29.62 \%)$, Sturge weber syndrome (14.81\%), Neurofibromatosis1 (NF1) (3.7\%) and Linear nevus syndrome (3.7\%).

In tuberous sclerosis complex $(n=13)$, most common features were facial angiofibroma (92.30\%),

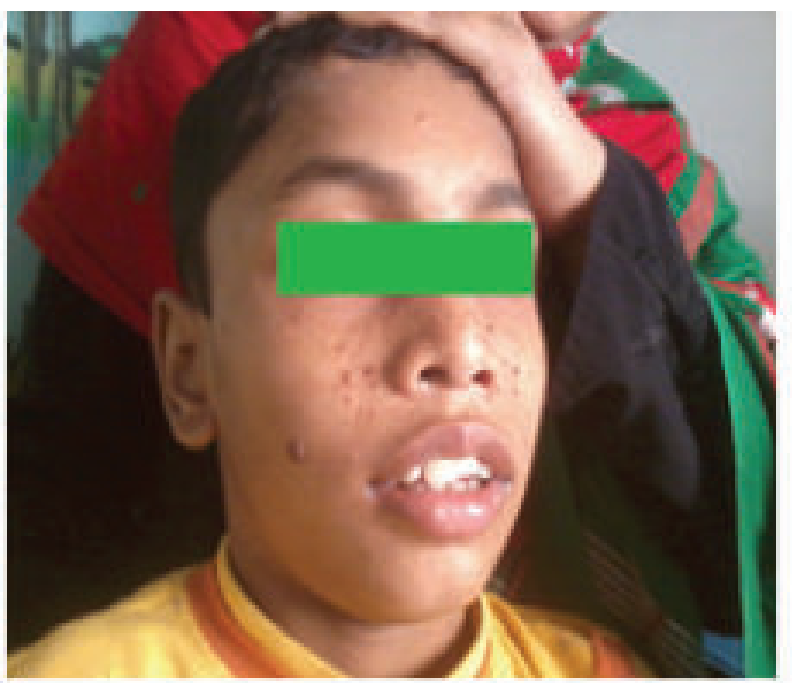

Fig.-1 : Facial angiofibroma (Tuberous sclerosis)

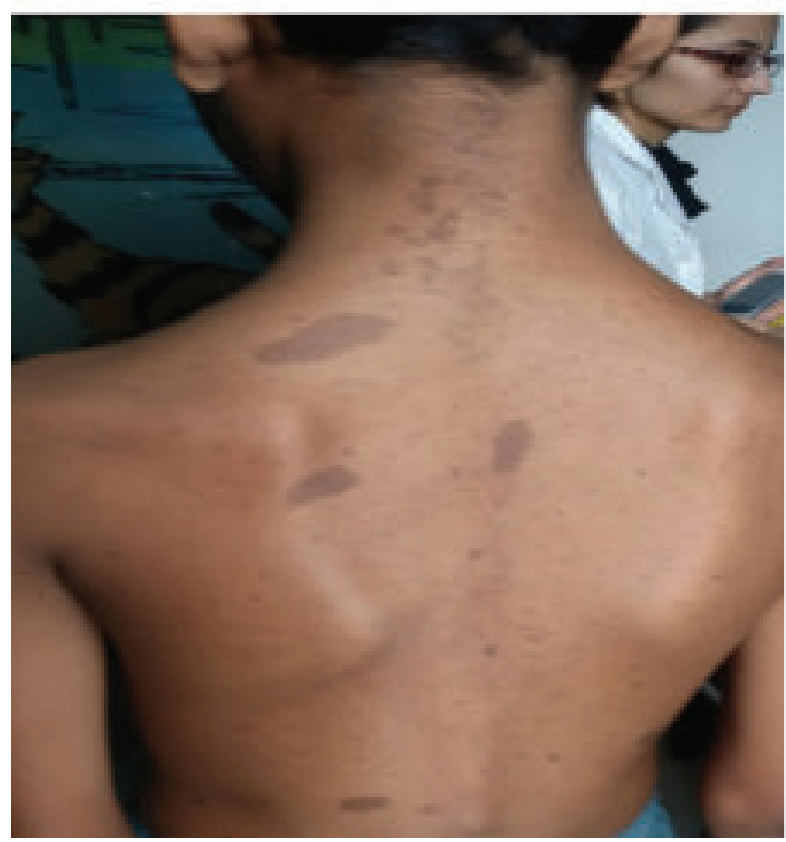

Fig.-3: Café-au-lait spot (Neurofibromatosis type-1), hypomelanotic macule $(76.90 \%)$, shagreen patch $(76.90 \%)$. In ataxia telangiectasia, common presentation was ataxia $(100 \%)$, ocular telangiectasia $(62.50 \%)$. In Sturge weber syndrome common presentation was facial capillary malformation $(100 \%)$. Neurofibromatosis was presented with neurofibroma $(100 \%)$, café-au-lait spot $(100 \%)$. Common systemic manifestations of NCS was found in TSC. Those were multicystic kidney disease (30.76\%), ASD (15.38\%) \& ADHD(7.69\%).

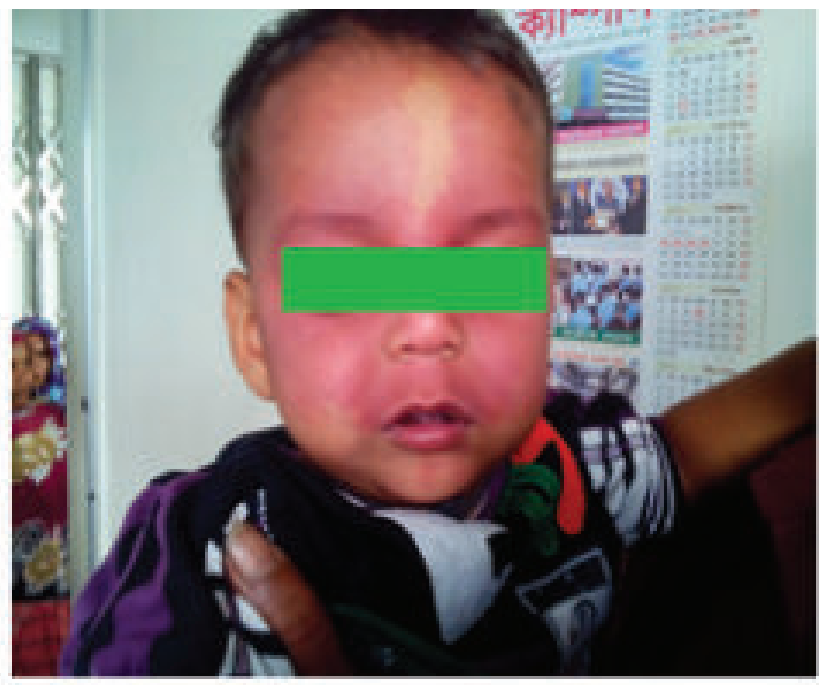

Fig.-1 : Port wine stain (Sturge weber syndrome)

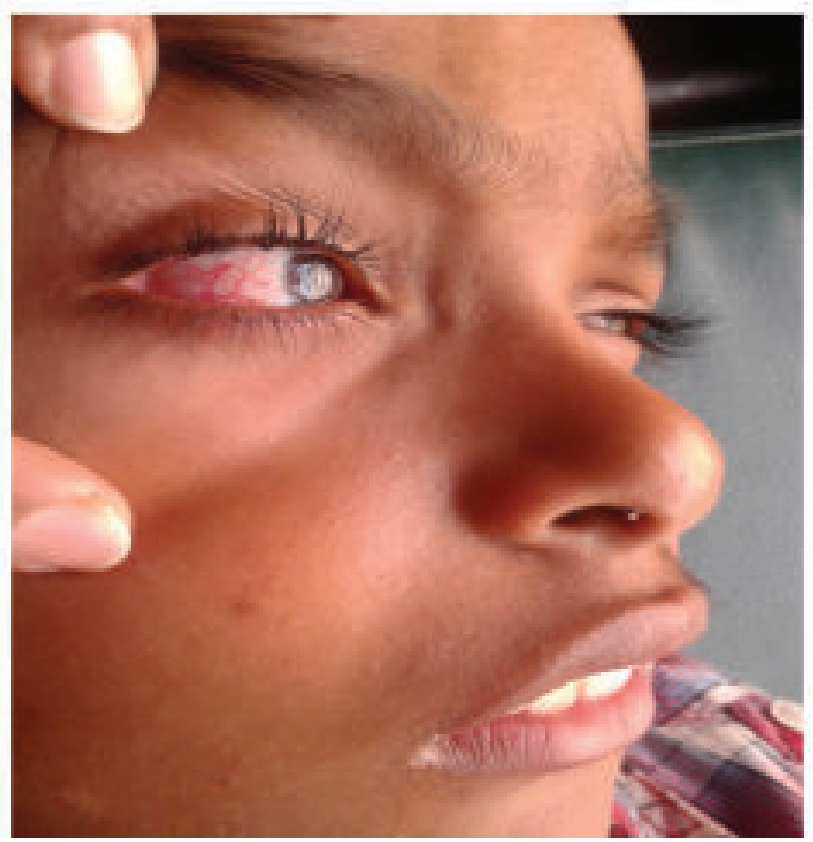

Fig.-4 : Telangiactasia in eye(Ataxia telangiectasia) 
Table I

Baseline characteristics and Clinical Features $(n=27)$.

\begin{tabular}{lc}
\hline Baseline characteristics & \\
\hline Median age (months) & 38.67 \\
Male ( $\mathrm{n} \%)$ & $59.26 \%$ \\
Female ( $\mathrm{n} \%)$ & $40.74 \%$ \\
Clinical characteristics & \\
Tuberous sclerosis complex (TSC) & $48.14 \%(13 / 27)$ \\
Ataxia telengiectasia (AT) & $29.62 \%(8 / 27)$ \\
Sturge Weber Syndrome (SWS) & $14.81 \%(4 / 27)$ \\
Neurofibromatosis-1 (NF1) & $3.7 \%(1 / 27)$ \\
Linear Nevus Syndrome (LNS) & $3.7 \%(1 / 27)$ \\
\hline
\end{tabular}

Table-I Showed base line characteristics of study population where male were more predominant and TSC was most common NCS.

\section{Table II}

Pattern of Cutaneous manifestations of various NCS.

\begin{tabular}{lc}
\hline Pattern of presentation & $\%$ of cases \\
\hline TSC (Total 13cases) & \\
Facial angiofibroma & $92.30 \%(12 / 13)$ \\
Hypomelanotic macule & $76.90 \%(10 / 13)$ \\
Shagreen patch & $76.90 \%(10 / 13)$ \\
SWS ( $n=4)$ & \\
Facial capillary malformation $(4)$ & $100 \%(4)$ \\
AT ( $n=8)$ & \\
Oculocutaneous tetengiactasia $(5)$ & $62.50 \%(5 / 8)$ \\
NF-1 ( $n=1)$ & \\
Neurofibroma & $100 \%(1 / 1)$ \\
Café- au-lait macules (CALMs) & $100 \%(1 / 1)$ \\
\hline
\end{tabular}

Table-II Showed different pattern of manifestation of various NCS.

Table III Common Systemic Manifestations in TSC ( $n=13)$.

\begin{tabular}{lc}
\hline $\begin{array}{l}\text { Co-morbidities / systemic } \\
\text { manifestations }\end{array}$ & Percentage (\%) \\
\hline Multicystic kidney disease & $30.76(4 / 13)$ \\
ASD & $15.38(2 / 13)$ \\
ADHD & $7.69(1 / 13)$ \\
\hline
\end{tabular}

Table - III Showed different systemic manifestation of NCS.

\section{Discussion}

There are different studies on various forms of NCS, but a collective study on them exclusively on the pediatric population is limited. TSC $13(48.14 \%)$ was the most common form of NCS in our study which were consistent to findings documented by Jozwiak $S$ et al., ${ }^{6}$. Skin lesions were the most frequently observed manifestations of TSC which were consistent with previous studies. ${ }^{6}$ The skin manifestations of TSC include facial angiofibroma, hypomelanotic macules, shagreen patches and periungual fibroma. In our study facial angiofibroma $12(92.30 \%)$ was the most common finding followed by hypomelanotic macules 10 (76.90\%) and shagreen patch $10(76.90 \%)$. Nearly similar findings were found in different studies 6,7 . Among renal manifestations only multicystic kidney disease 4 in number $(30.76 \%)$ were found in our study but in other studies angiomyolipoma was the most common finding of TSC followed by multicystic kidney disease. ${ }^{8}$ This discrepancy may be due to small sample size and also it was a single centered study. Among neurological manifestations we found Autism Spectrum disorder 2 (15.38\%) and Attention Deficit Hyperactivity Disorder 1 (7.69\%). This frequency is consistent with other studies. But Epilepsy is the most common neurological manifestation in other studies, ${ }^{9}$ though we did not find any case having epilepsy in our study.

There have been various studies on clinical profile of NF1 both in children as well as in adults. ${ }^{5,7,8,9}$ In our series, we found only $1(3.7 \%)$ case of Neurofibromatosis. Cutaneous manifestation were Café-au-lait macules (100\%) and Neurofibroma $(100 \%)$. Nearly similar findings were documented by Neerja Puri. ${ }^{10-15}$

Sturge-weber syndrome is the only form of NCS that is not genetically determined. We found $4(14.81 \%)$ patients of Sturge weber syndrome. Only facial capillary malformation $(100 \%)$ was found as clinical manifestation. These percentages were near similar to the findings found in previous study ${ }^{16}$. But we did not find neurological manifestations like epilepsy, mental retardation, hemiparesis and ophthalmological manifestations like glaucoma or buphthalmos. This discrepancy may be due to small sample size and less incidence of the disease.

Ataxia-telangiectasia (AT) is an autosomal recessive inherited disease caused by the mutational 
inactivation of the ATM gene. We found 8 (29.62\%) patients having AT. It is $2^{\text {nd }}$ most common syndrome in our study. These findings were more frequent than the findings documented by Radheshyam Purkit et al., Ataxia was the most common presentation $(100 \%)$ followed by oculocutaneous tetengiactasia $(62.50 \%)$. Similar findings were found in previous studies $^{17-20}$

Linear nevus syndrome is a very rare neurocutaneous syndrome. We found $1(3.7 \%)$ in our study. Majority of the study on neurocutaneous syndrome did not find this syndrome in their study.

As neurocutaneous syndrome is not uncommon in the pediatric population, when a child present with any neurocutaneous marker dermatologists should look for any neurological manifestations, or any cognitive dysfunction those are often missed. However, at the same time the neurologists must also be sensitized about performing a dermatological examination in a child with central nervous system involvement.

\section{Conclusion}

In our study, the commonest neuro-cutaneous syndrome was TSC and facial angiofibroma was the most common manifestation of TSC. Ataxia telangiectasia and Sturge weber Syndrome were also common. Neuro-cutaneous syndrome can be diagnosed early by searching subtle cutaneous signs.

\section{References}

1. Dahan D, Fenichel GM, El-Said R. Neurocutaneous syndromes. Adolesc Med 2002; 13:495-509.

2. H Robert HA. Neurocutaneous Syndromes. In: Kliegman RA, Jenson HB, Behrman RE, Stanton BF, editors. Nelson Textbook of Pediatrics. $18^{\text {th }}$ ed. Vol. 2. Philadelphia: Elsevier; 2008. pp. 2483-8.

3. Borkowska J, Schwartz RA, Kotulska K. Tuberous sclerosis complex:tumors and tumorigenesis. Int J Dermatol 2011; 50: 13-20.

4. Dabora SL, Jozwiak S, Franz DN. Mutational analysis in a cohort of 224 tuberous sclerosis patients indicates increased severity of TSC2, compared with TSC1, disease in multiple organs. Am J Hum Genet 2001; 68: 64-80.
5. Ball LG. Molecular basis of ataxia telangiectasia and related diseases. ActaPharmacol Sin. 2005; 26: 897-907.

6. Jozwiak S, Schwartz RA, Janniger CK, Michalowicz R, Chmielik J. Skin lesions in children with tuberous sclerosis complex: their prevalence, natural course, and diagnostic significance. Int J Dermatol 1998; 37: 911-7.

7. Kingswood C, Bolton P, Crawford P. The clinical profile of tuberous sclerosis complex (TSC) in the United Kingdom: A retrospective cohort study in the Clinical Practice Research Datalink (CPRD). Eur J Paediatr Neurol. 2016 ; 20:296308.

8. Rakowski SK, Winterkorn EB, Paul E, Steele DJ. Renal manifestations of tuberous sclerosis complex: Incidence, prognosis, and predictive factors. Kidney Int. 2006;70:1777-82.

9. Franz DN, Bissler JJ, McCormack FX. Tuberous Sclerosis Complex: Neurological, Renal and Pulmonary Manifestations. Neuropediatrics 2010; 41: 199-208.

10. Puri N. A Study of Clinical Profile of Neurofibromatosis. JIMSA 2013; 26 : 103-5.

11. J Med Genet. A genetic study of von Recklinghausen neurofibromatosis in south east Wales.revalence, fitness, mutation rate, and effect of parental transmission on severity. Journal of Medical Genetics1989; 26:704-11.

12. .Obringer AC, Meadows AT, Zackai EH. The diagnosis of neurofibromatosis 1 in the child under the age of 6 years. Am J Dis Child 1989; 143:717-9.

13. Créange A, Zeller J, Rostaing-Rigattieri S. Neurological complications of neurofibromatosis type 1 in adulthood. Brain 1999; 122:473-81.

14. North K. Neurofibromatosis type 1: Review of the first 200 patients in an Australian clinic. J Child Neurol 1993; 8:395-402.

15. Nunley KS, Gao F, Albers AC, Bayliss SJ, Gutmann DH. Predictive value of café au lait macules at initial consultation in the diagnosis of neurofibromatosis type 1 . Arch Dermatol 2009; 145:883-7. 
16. Maruani A. Sturge-Weber syndrome. Presse Med 2010; 39:482-6.

17. Bott L, Thumerelle C, Cuvellier JC, Deschildre A, Vallée L, Sardet A. Ataxia-telangiectasia: A review. Arch Pediatr 2006; 13:293-8.

18. Rothblum-Oviatt C, Wright J, Lefton-Greif MA, McGrath-Morrow SA, Crawford TO, Lederman HM. Ataxia telangiectasia: a review. Orphanet J Rare Dis. 2016 Nov 25;11:159.
19. Hélio A. G. Teive, Moro A, Moscovich M, Renato P. Munhoz, and Ashizawa Ataxia-telangiectasia - A historical review and a proposal for a new designation: ATM syndrome. J Neurol Sci. 2015; 15; 355 :3-6.

20. Purkait R, Samanta T, Thakur S, Dhar S. Neuro-cutaneous Syndrome: A Prospective study. Indian journal of Darmatology 2011; 56:375-9. 